\title{
FLAVONOID CONSTITUENTS OF THE MATURE FRUIT OF TETRAPLEURA TETRAPTERA SCHUM. ET THONN.)
}

\author{
T.C. Fleischer ${ }^{1}$, G. Komlaga ${ }^{1}$, A.Y. Mensah ${ }^{1}$, M.L.K. Mensah ${ }^{1}$, E. Wood $^{2}$ \\ I.K. Sawer ${ }^{3}$ and A.I. Grey ${ }^{4}$ \\ ${ }^{1}$ Department of Pharmacognosy, Faculty of Pharmacy and Pharmaceutical Sciences, \\ KNUST., Kumasi, Ghana \\ ${ }^{2}$ Department of Pharmacology, Faculty of Pharmacy and Pharmaceutical Sciences, \\ KNUST., Kumasi, Ghana \\ ${ }^{3}$ Department of Pharmaceutics, Faculty of Pharmacy and Pharmaceutical Sciences, \\ KNUST., Kumasi, Ghana \\ ${ }^{4}$ Department of Pharmaceutical Sciences, University of Strathclyde, Glasgow, Scotland
}

\begin{abstract}
Phytochemical investigation of the ethanolic extract of the mature fruit of Tetrapheura tetraptera led to the isolation of three flavonoid constituents namely 2', 4, 4'-trihydroxychalcone, 2', 3, 4, 4'-

tetrahydroxychalcone and 4', 5, 7-trihydroxyflavanone. The structures were established from 1D and 2D NMR experiments. This is the first isolation of flavonoid constituents in the genus Tetrapleura.
\end{abstract}

Keywords: Tetrapheura tetraptera, flavonoid, chalcone, flavanone, $1 D$ and $2 D$ NMR.

\section{INTRODUCTION}

Tetraphera tetraptera (Schum. Et Thonn.) (Mi-mosaceae) is a tree that grows in the tropical deciduous forest of West Africa, extending from Senegal to West Cameroon; and also found in Sudan, Uganda and Zaire (Burkill, 1995). In West Africa, the fruit is widely used in traditional remedies for the treatment of several conditions including convulsion, gastric ulcer, rheumatism, fevers, whitlow, skin rashes, smallpox, malaria and dysentery (Dalziel, 1995, Irvine, 1961, Abbiw, 1990). Previous phytochemical studies revealed the presence of triperpene saponins of the oleanane type (Adesina and Sofowora, 1979; Mailland et al, 1992 Ngassapa et al., 1993). The occurrence of flavonoids and other classes of secondary metabolites have been reported only in the stem bark (El-izzi et al., 1990). Recently we have taken keen interest in the chemistry and pharmacology of the fruit of Tetrapheura tetraptera because of the reports that it is used to manage diabetes and cardiovascular diseases like hypertension and stroke in some traditional societies of Ghana (Amoako-Atta B., Director - CBUD, KNUST, personal communication, 2001). In this report we present the isolation and characterization of three flavonoid constituents from the ethanolic extract of the fruit.

\section{MATERIALS AND METHODS}

\section{General}

1D and 2D NMR spectra were obtained on a Bruker AMX - 400 spectrometer operating at $400 \mathrm{MHz}\left({ }^{1} \mathrm{H}-\right.$ $\mathrm{NMR})$ and $100 \mathrm{MHz}\left({ }^{13} \mathrm{C}-\mathrm{NMR}\right)$. The NMR experiments performed included proton nuclear magnetic resonance $\left({ }^{1} \mathrm{H}-\mathrm{NMR}\right),{ }^{13} \mathrm{C}$-nuclear magnetic resonance $\left({ }^{13} \mathrm{C}-\mathrm{NMR}\right)$, Homonuclear Correlation Spectroscopy $\left({ }^{1} \mathrm{H}-{ }^{1} \mathrm{H}\right.$ COSY), Heteronuclear Multiple Bond Connectivity (HMBC) and Nuclear Overhauser Effect (NOESY). The $J$-modulated ${ }^{13} \mathrm{C}$-spectra were acquired with a relaxation time $\left(d_{1}\right)$ of 6 sec. The HMBC spectra were optimised for long range $J_{\mathrm{H}-\mathrm{C}}$ of $7 \mathrm{~Hz}\left(d_{6}=0.007 \mathrm{sec}\right)$. The ${ }^{1} \mathrm{H}-\mathrm{NMR}$ and ${ }^{13} \mathrm{C}-\mathrm{NMR}$ chemical shifts were referenced to solvent signals at $\delta_{\mathrm{C} / \mathrm{H}} 7.27 / 77.0\left(\mathrm{CDCI}_{3}\right)$ and 4.78/49.0 $\left(\mathrm{CD}_{3} \mathrm{OD}\right)$ relative to TMS.

Column chromatography was carried out using Merck Silica gel 40. Preparative TLC was carried out using Merck Silica gel $60 \mathrm{PF}_{254}$ on glass plates $(20 \mathrm{X} 20 \mathrm{~cm})$ at a thickness of $0.5 \mathrm{~mm}$. TLC was conducted on Merck Silica gel $60 \mathrm{~F}_{254}$ pre-coated on aluminium sheet.

\section{Plant Material}

Mature dried fruits of Tetrapheura tetraptera (Mimosaceae) were supplied in February 2002, by the Centre for Biodiversity Utilization and Development (CBUD), KNUST, a centre for promoting the valorisation of the fruits in indigenous societies in Ghana. 


\section{Extraction and Isolation}

The fruits of T. tetraptera were cut into smaller pieces and dried in a hot air oven at $50^{\circ} \mathrm{C}$ after which the dried material was milled to a coarse powder was soxhlet extracted with $70 \% \mathrm{EtOH}$ for 12 hours. The extract was concentrated to a dark brown viscous liquid under reduced pressure using the Rotavapor. The liquid extract was further evaporated to a semisolid mass (Yield: $34.13 \% \mathrm{w} / \mathrm{w}$ ). $100 \mathrm{~g}$ of the extract was column chromatographed over silica gel, eluting sequentially in $100 \mathrm{ml}$ aliquots with petroleum ether followed by $20 \%$ and $50 \%$ ethyl acetate in petroleum ether, ethyl acetate, $20 \%$ and then $50 \%$ methanol in ethyl acetate. They were then bulked together, based on their TLC profiles, to give fractions A to F. Further column chromatographic fractionation of fraction D $(7.44 \mathrm{~g})$ on silica gel and preparative TLC using petroleum ether: ethyl acetate (6:4) as solvent system led to the isolation of 2', 4', 4-tetrahydroxychalcone (17.0mg) (1), and a mixture of 2', 4, 4'-trihy-droxychacone (2) and 4', 5, 7-trihydroxy-flavanone (8.5mg) (3).

\section{RESULTS AND DISCUSSION}

Compound 1 was obtained as yellow amorphous solid, melting point $210-218^{\circ} \mathrm{C}$ (uncorrected). The ${ }^{1} \mathrm{H}$ NMR spectrum obtained in pyridine (Table 1) showed 6 aromatic signals at $\delta 8.13(d j=8.9 \mathrm{~Hz}), \delta 7.80(d$ $J=1.9 \mathrm{~Hz}), \delta 7.36(d d J=2.0 \mathrm{~Hz}, 8.2 \mathrm{~Hz}), \delta 7.28(d J=8.12 \mathrm{~Hz}), \delta 6.89(d J=2.32 \mathrm{~Hz})$ and $\delta 6.78(d d J=2.3$ $\mathrm{Hz}, 8.8 \mathrm{~Hz})$. It also showed two trans-coupling olefinic protons at $\delta 8.24(d J=15.2 \mathrm{~Hz})$ and $\delta 7.88(d J=15.2$ $\mathrm{Hz}$ ), and a singlet at $\delta 14.42$ typical of extended hy-drogen bonding in 2'hydroxychalcones (Mabry et al., 1970; Fleischer et al., 1997). The $J$-modulated ${ }^{13} \mathrm{C}$ NMR spectrum (Table 1) revelaed a carbonyl fucntion at $\delta 192.8$, eight olefinic/aromatic methines at $\delta 146.1, \delta 133.3, \delta 123.4, \delta 118.3, \delta 117.3, \delta 117.0 \delta 104.5, \delta$ 109.6 , four oxygenated aromatic carbon signals at $\delta 148.3, \delta 151.5, \delta 168.0$, and $\delta 167.1$, and two quaternary aromatic signals at $\delta 128.0$ and $\delta 114.6$. This suggested a molecular formula of $\mathrm{C}_{15} \mathrm{H}_{12} \mathrm{O}_{5}$ for compound $\mathbf{1}$. The COSY 90 spectrum (Fig. 1), revealed all the possible ${ }^{1} \mathrm{H}-{ }^{1} \mathrm{H}$ correlations. In the HMBC experiment, the trans-coupled olefinic protons at $\delta 7.88(\mathrm{H}-\alpha)$ and $\delta 8.24(\mathrm{H}-\beta)$ showed ${ }^{2} J$ and ${ }^{3} J$ correlations respectively, with the carbonyl carbon (Fig. 2), confirming the characteristic propenone struc-ture in chalcones. $\mathrm{H}-\alpha$ and $\mathrm{H}-\beta$ also showed ${ }^{3} J$ and ${ }^{2} J$ correlations respectively with the qua-ternary aromatic carbon at $\delta 128.0(\mathrm{C}-1)$, confirming that the $\mathrm{C}-\beta$ of the propenone chain is linked to ring $\mathrm{B}$. This carbon signal (C-1) further correlated $\left({ }^{2} J\right)$ with the proton doublet at $\delta 7.80(\mathrm{H}-2)$ and the doublet of doublet at $\delta 7.36(\mathrm{H}-6)$. The long range correlations between $2^{\prime}-$ 
Table 1: ${ }^{1} \mathrm{HNMR}$ and ${ }^{13} \mathrm{C}$ NMR data for 1 and 2

\begin{tabular}{|c|c|c|c|c|}
\hline \multirow[t]{2}{*}{ Position } & \multicolumn{2}{|c|}{$\delta_{\mathrm{H}}$} & \multicolumn{2}{|c|}{$\delta_{\mathrm{C}}$} \\
\hline & 1 & 2 & 1 & 2 \\
\hline 1 & & & 128.0 & 126.5 \\
\hline 2 & $7.80(d, J=1.9 \mathrm{~Hz})$ & $7.43(d, J=8.6 \mathrm{~Hz})$ & 117.0 & 130.6 \\
\hline 3 & & $6.76(d, J=8.5 \mathrm{~Hz})$ & 148.3 & 116.0 \\
\hline 4 & & & 151.5 & 159.8 \\
\hline 5 & $7.28(d, J=8.1 \mathrm{~Hz})$ & $6.76(d, J=8.5 \mathrm{~Hz})$ & 117.3 & 116.0 \\
\hline 6 & $7.36(d d, J=1.96 \mathrm{~Hz}, 8.16 \mathrm{~Hz})$ & $7.43(d, J=8.6 \mathrm{~Hz})$ & 123.4 & 130.6 \\
\hline$\alpha$ & $8.24(d, J=15.24 \mathrm{~Hz})$ & $7.64(d, J=15.3 \mathrm{~Hz})$ & 118.3 & 117.2 \\
\hline$\beta$ & $7.88(d, J=15.24 \mathrm{~Hz})$ & $7.33(d, J=15.3 \mathrm{~Hz})$ & 146.1 & 144.6 \\
\hline $\mathrm{C}=\mathrm{O}$ & & & 192.8 & 192.1 \\
\hline $1^{\prime}$ & & & 114.6 & 113.6 \\
\hline 2'-OH & $14.42(s)$ & & 168.0 & 165.8 \\
\hline $3^{\prime}$ & $6.89(d, J=2.32 \mathrm{~Hz})$ & $6.26(d, J=2.3 \mathrm{~Hz})$ & 104.5 & 103.1 \\
\hline $4^{\prime}$ & & & 167.1 & 164.6 \\
\hline $5^{\prime}$ & $6.78(d d, J=2.28 \mathrm{~Hz}, 8.8 \mathrm{~Hz})$ & $6.32(d d, J=2.3 \mathrm{~Hz}, 8.8 \mathrm{~Hz})$ & 109.6 & 108.3 \\
\hline $6^{\prime}$ & $8.13(d, J=8.88 \mathrm{~Hz})$ & $7.71(d, J=8.8 \mathrm{~Hz})$ & 133.3 & 131.9 \\
\hline
\end{tabular}

Fig. 1: Structures of compounds 1-3. 2', 4, 4'- trihydroxychalcone(1), 2', 3, 4, 4'-tetrahyxychalcone (2) and 4 ', 5, 7-trihydroxyflavanone (3).
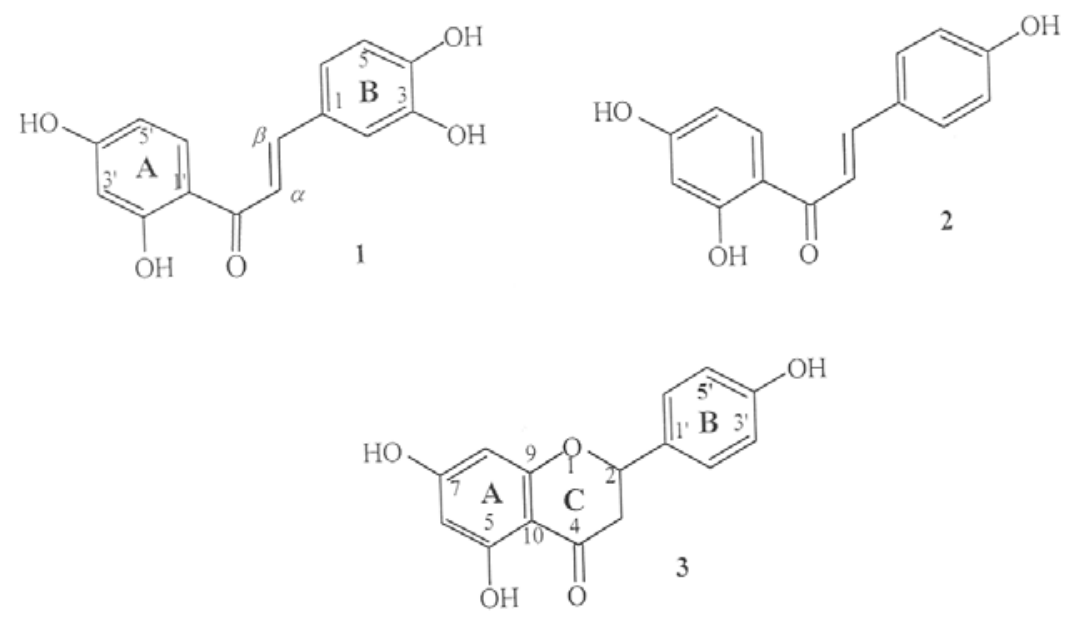
Table 2: ${ }^{1} \mathrm{H}-\mathrm{NMR}$ and ${ }^{13} \mathrm{C}$ NMR data for 3

\begin{tabular}{ccr}
\hline Pos. & \multicolumn{1}{c}{$\delta_{\mathbf{H}}$} & $\delta_{\mathbf{C}}$ \\
\hline 2 & $5.2(d d, J=3.0 \mathrm{~Hz}, 13.0 \mathrm{~Hz})$ & 79.1 \\
3 & $2.62(d d, J=3.0 \mathrm{~Hz}, 17.2 \mathrm{~Hz}[\mathrm{H}-3 \mathrm{eq}])$ & 43.0 \\
& $2.97(d d J=13 \mathrm{~Hz}, 17.2 \mathrm{~Hz}[\mathrm{H}-3 \mathrm{ax}])$ & \\
4 & & 196.2 \\
5 & & 163.9 \\
6 & $5.86(s)$ & 96.4 \\
7 & & 166.9 \\
8 & $5.85(s)$ & 95.6 \\
9 & & 163.3 \\
10 & & 102.4 \\
$1^{\prime}$ & & 129.4 \\
$2^{\prime}$ & $7.18(d, J=8.6 \mathrm{~Hz})$ & 127.9 \\
$3^{\prime}$ & $6.76(d, J=8.5 \mathrm{~Hz})$ & 115.6 \\
$4^{\prime}$ & & 157.4 \\
$5^{\prime}$ & $6.76(d, J=8.5 \mathrm{~Hz})$ & 115.6 \\
$6^{\prime}$ & $7.18(d, J=8.6 \mathrm{~Hz})$ & 127.9
\end{tabular}

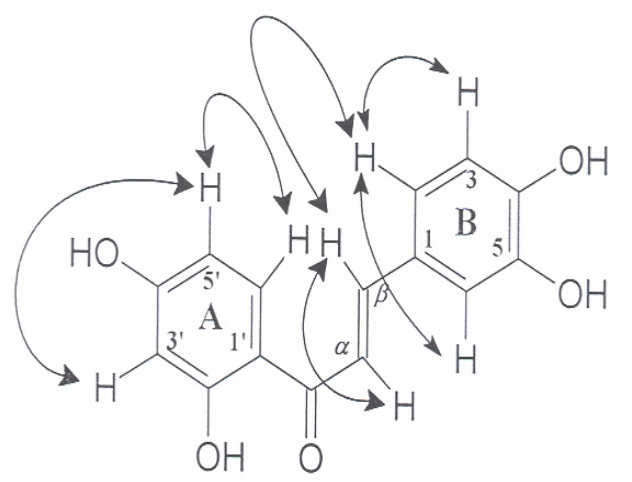

\section{Fig. 2: Important ${ }^{1} \mathrm{H}-{ }^{1} \mathrm{H}$ COSY coupling in 1}

OH $\left({ }^{2} J\right)$ and H-6 $\left({ }^{3} J\right)$ with C-2' confirmed the assignments. Other confirmatory long range correlations are shown in Fig. 2. The absence of relevant signals in the ${ }^{1} \mathrm{H}$ and ${ }^{13} \mathrm{C}$ NMR spectra suggested that the substituents on the three oxygenated quaternary aromatic carbons should be hydroxyl groups. Compound 1 was thus identified as the known 2', 3, 4, 4'-tetrahydroxy-chalcone which is trivially referred to as butein, previously isolated from various plant species including Dalbergia odorigera, (Cheng et al. 1998). The spectral data of 1 were in accordance with those published (Sritularak, et al., 2002).

Fig. 3: Some significant long range $\left({ }^{2} J\right.$ and $\left.{ }^{3} J\right)$ correlations in the HMBC spectrum of 1

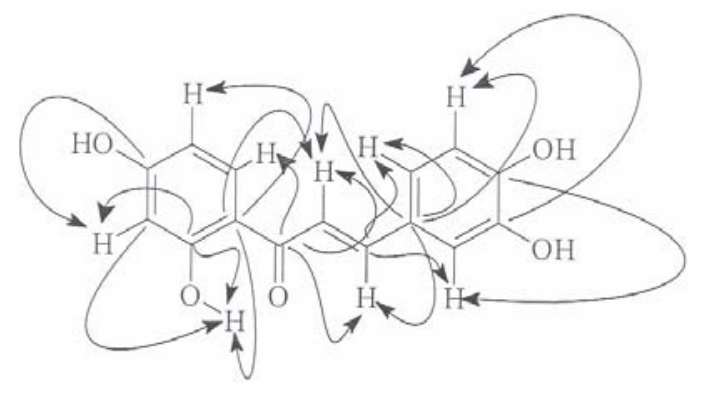


Compounds $\mathbf{2}$ and $\mathbf{3}$ were obtained as a mixture with $\mathbf{2}$ as the major component. The mixture occurred as a yellow amorphous solid, which melted at 240-251 (uncorrected). The spectral data of $\mathbf{2}$ were similar to that of 1. The ${ }^{1} \mathrm{H}$ NMR spectrum in $\mathrm{CD}_{3} \mathrm{OD} / \mathrm{CD}_{3} \mathrm{OD}$ (Table 1) showed the typical trans-coupled olefinic protons $(\mathrm{H}-\alpha$ and $\mathrm{H}-\beta)$ of the propenone moiety of the chalcone at $\delta 7.64(d, J=15.3)$ and $\delta 7.33(d, J=$ $15.3 \mathrm{~Hz})$. It also exhibited two aromatic doublets at $\delta 7.43(d, J=8.6 \mathrm{~Hz})$, and $\delta 6.76(d, J=8.5 \mathrm{~Hz})$, each integrating for two protons, characteristic of an $\mathrm{A}_{2} \mathrm{X}_{2}$ system of para-distributed phenyl ring. It further revealed a doublet of doublets at $\delta 6.32(d d, J=2.3 \mathrm{~Hz}, 8.8 \mathrm{~Hz})$ which meta-coupled with a doublet at $\delta 6.26$ $(d, J=2.3 \mathrm{~Hz})$ and ortho-coupled with another at $\delta 7.71(d, J=8.8 \mathrm{~Hz})$ to give a trisubstituted phenyl ring. The ${ }^{13} \mathrm{CNMR}$ spectrum (Table 1) showed the presence of carbonyl carbon at $\delta 192.1(\mathrm{C}=\mathrm{O})$, two olefinic carbon signals at $\delta 144.6(\mathrm{C}-\beta)$ and $\delta 117.2(\mathrm{C}-\alpha)$, confirming the propenone submit of chalconesas in 1 . It also revealed three oxygenated aromatic carbons at $\delta 159.8, \delta 164.6$ and $\delta 165.8$ and other aromatic signals, giving the molecular formula of 2 as $\mathrm{C}_{15} \mathrm{H}_{12} \mathrm{O}_{4}$. the COSY 90 spectrum revealed all the possible ${ }^{1} \mathrm{H}-{ }^{1} \mathrm{H}$ correlations. The structure was established with the HMBC experiment. In this spectrum, the carbonyl carbon exhibited ${ }^{2} J$ and ${ }^{3} J$ correla-tions with the olefinic protons at $\delta 7.33(\mathrm{H}-\alpha)$ and $\delta 7.64(\mathrm{H}-\beta)$ respectively. It also showed a ${ }^{3} J$ correlation between the carbonyl carbon at $\beta 192.1$ and the trisubstituted phenyl proton at $\delta 7.71\left(\mathrm{H}-6^{\prime}\right)$ while the olefinic carbon at $\delta 144.6(\mathrm{C}-\beta)$ showed ${ }^{3} J$ correlations with the H$2 / 6$ of the $p$-disubstituted benzene ring. The substi-tuents on the three oxygenated aromatic carbons of the phynyl rings must be $\mathrm{OH}$ groups, since there were no relevant signals in the ${ }^{1} \mathrm{H}$ NMR and ${ }^{13} \mathrm{C}$ NMR spectra. The expected extended hydrogen bonding signal for $2^{2}$-hydroxychal-cones in the ${ }^{1} \mathrm{H}$ NMR spectrum of 2, was not evident due to deuterium exchange. Compound 2 was thus identified as 2', 4, 4'trihydroxychal-cone (isoliquiritigenin) which was previously isolated from Glycyrrhiza glabra (Aida et al. 1990) and Pterocarpus indicus (Kusuma et al., 2004). A comparison of the spectral data of 2 with that of the literature (Veitch et al, 2003) confirmed the structure.

Compound $\mathbf{3}$, the minor component of the mixture, give proton signals that were identical and sometimes overlapped with those of $\mathbf{2}$. The ${ }^{1} \mathrm{H}$ NMR spectrum which was typical of a flavenone, showed two aromatic doublets centred at $\delta 7.18 d, J=8.6 \mathrm{~Hz}\left(\mathrm{H}-2^{\prime} / 6^{\prime}\right)$ and $\delta 6.76 d, J=8.5 \mathrm{~Hz}\left(\mathrm{H}-3^{\prime} / 5^{\prime}\right)$ characteristic of the $p$ disubstituted benzene ring system, an aromatic singlet at $\delta 5.85$ which integrated for two protons and assignable to H-6 and H-8 of ring a of a flavanone, and the typical flavanone ABX system at $\delta 5.20$ ( $d d$, $J=3.0 \mathrm{~Hz}, 13.0 \mathrm{~Hz}), \delta 2.62\left(d d, J=3.0 \mathrm{~Hz}\right.$ ) and $\delta 2.97$, (dd, $J=13.0 \mathrm{~Hz}, 17.2 \mathrm{H}$.) (Mabry et al., 1970). The ${ }^{13} \mathrm{C}$ NMR spectrum (Table 2) showed signals for a carbonyl function at $\delta 196.2$, four oxygenated aromatic carbons at $\delta 163.9, \delta 163.3, \delta 166.9$ and $\delta 157.4$, two aromatic tertiary carbons at $\delta 129.4$ and $\delta 102.4$, an oxygenated methine carbon at $\delta 79.1$ and methylene signal at $\delta 43.0$, and six aromatic methines, providing for the molecular formula $\mathrm{C}_{15} \mathrm{H}_{12} \mathrm{O}_{5}$. The flavanone struture was confirmed by the presence of the carbonyl sginal at $\delta 196.2$ assignable to $\mathrm{C}-4$, the oxygenated methine and methylene signals at $\delta 79.1$ and $\delta 43.0$ allocated to C-2 and C-3 respectively in the ${ }^{13} \mathrm{C}$ NMR spectrum (Agrawal, 1989). Analysis of the 2D NMR experiments $\left({ }^{1} \mathrm{H}-{ }^{1} \mathrm{H}\right.$ COSY, HMBC and ${ }^{1} \mathrm{H}-{ }^{1} \mathrm{H}$ NOESY spectra) supported the proton and carbon assignments. The other substituents on the phenyl ring subunits must be $\mathrm{OH}$ groups which were confirmed by the presence of oxygenated quaternary aromatic carbons at $\delta 163.9(\mathrm{C}-5), \delta 166.9(\mathrm{C}-7)$ and $\delta 157.4(\mathrm{C}-$ $\left.4^{\prime}\right)$, and the lack of relevant signals in the ${ }^{1} \mathrm{H}$ NMR and ${ }^{13} \mathrm{C}$-NMR spectra. In the ${ }^{1} \mathrm{H}$ NMR spectrum the expected extended H-bonding signal for 5-hydroxyflavanones did not show because of deuterium exchange. The structure of 3 was thus established as the known 4', 5, 7-trihydroxyflavanone (naringenin). The spectral data of compound $\mathbf{3}$ was consistent with those published (Shen et al., 1993).

The isolation of these flavonoids from the fruits of Tetrapleura tetraptera is noteworthy. This is the first report of the isolation of such consti-tuents from the genus Tetrapleura, although as a class of secondary metabolites, flavonoids have been reported to occur in some parts of $T$. tetraptera including the stem bark (El-izzi et al., 1990). Secondly, the isolated flavonoids have demonstrated various biological activities. For example butein 1 has been shown to be a potent antioxidant and an anti-inflammatory agent (Cheng et al., 1998). Isoliquiritigenin 2 has shown vasorelaxant activity on the phynyleph-rine-precontracted rat aorta (Yu and Kuo, 1995), aldose reductase inhibiting activity (Aida et al., 1990) and is also a potent anti-tumorpromoting and anti-inflammatory agent (Yamamoto et al., 1991). Naringenin $\mathbf{3}$ has been shown to lower plasma cholesterol in vivo (Lisa et al., 2001) and also have antioxidant and hypoglycaemic properties (Ali and El Kader, 2004). Thus the presence of these constituents in the fruit of T. tetrapheura could be said to have contributed to the hypoglycaemic effect of the extract observed in our laboratory (Komlaga et al., 
2004), and justifies the use of the fruit in the management of diabetes and hypertension in folklore medicine in Ghana.

\section{ACKNOWLEDGEMENT}

We wish to acknowledge Centre for Biodiversity Utilization and Development (CBUD), Kwame Nkrumah University of Science and Technology (KNUST) for partly supportng this work. NMR spectra were run by the Phytochemistry Research Laboratories, Department of Pharma-ceutical Sciences, University of Strathclyde, UK.

\section{REFERENCES}

Abbiw, D (1990). Useful plants of Ghana. West African use of wild and cultivated plants. Intermediate Technology Publications and the Royal Botanic Gardens, KEW. UK.52: 156.

Adesina, S.K. and Sofowora, E.A. (1979). The isolation of an anticonvulsant glycoside from the fruit of Tetrapleura tetraptera. Planta Medica. 36, 270-1.

Agrawal, P.K. (1992). NMR spectroscopy in the structure elucidation of oligosaccharides and glycosides. Phytochemistry, 31, 3307.

Aida K. Tawata N. Shindo . Onaya T, Sasaki H. Yamaguchi T, Chin M, Mitsuhashi H. (1990) Isoliquiritigenin: a newaldose reduc-tase inhibitor from Glycyrrhiza radix. Planta Medica. 56 254-8.

Aldrick Library of ${ }^{13} \mathrm{C}$ and ${ }^{1} \mathrm{H}$ FT NMR spectra (1992) 2, 915C.

Ali, M.M. and El Kader, M.A. (2004). The influence of naringenin of the oxidative state of rats with streptozotocin - induced acute hyperglycaemia. Z. Naturforsch 59, 726-733.

Burkill, H.M. (1995). The useful plants of West Tropical Africa. 2nd ed., royal Botanic Gardens, Kew, pp 263-265.

Cheng Z.J., Kuo S.C., Chan S.C., Ko F.N., Teng C.M. (1998). antioxidant properties of butein isolated from Dalbergia odorifera, Biochim Biophys Acta. 1392, 291-9.

Dalziel, J.M. (1955). The Useful Plants of West Tropical Africa, Crown Agents for Ovrseas Governments and Administrations. pp. 223-224.

El-izzi, A.: Benie, T.: Thieulant, M.L. and Duval, J. (1990). Inhibitory effects of saponins from T. tetraptera on the Luteini-zing Hormone release by cultural rat pituitary cells. Planta Medica 56: 359.

Fleischer, T.C., Waigh, R.D. and waterman, P.G. (1997). A novel retrodihydrochalcone from the stem bark of Uvaria mocoli L., Phytochemistry, 47 1387-1391.

Irvine, F.R. (1961). Woody plants of Ghana with special reference to their uses. Oxford University Press, London, 58.

Lisa J. Wilcox, Nica M. Borradaile, Linda E. de Dreu, and Murray W. Huff (2001). Secretion of hepatocyte apoB is inhibited by the flavonoids, naringenin and hesperetin, via reduced activity and expression of ACAT2 and MTP, Journal of Lipid Research, 42 725-734.

Komlaga, G., Sarpong, K., Mensah, M.L.K., Mensah, A.Y., Wood, E., Sawer, I.K. and Fleischer, t.C. (2004). Hypoglycaemic activity of the alcoholic fruit extract of Tetrapleura tetraptera in normoglycaemic albino rats, (an oral presentation made at the Western African Network of Natural products Research Scientists, WANNPRES, 15-20 August, 2004, in Accra.

Kusuma I.W., Ogawa T., Itoh K. and Tachibana S. (2004). Isolation and Identification of an Antifungal Sesquiterpene Alcohol from Amboyna Wood Pakistan Journal of Biological Sciences 7 1735-1740.

Mabry, J.T, Markham, K.R. and Thomas, M.B. (1970). The systematic identification of flavonoids, Springler, New York Inc.

Maillard, M., Adewunmi, C.O. and Hostettmann K. (1992). A triterpene glycoside from the fruits of $T$. tetraptera. Phytochemistry, 31, 1321-1323.

Ngassapa, O., Beecher, C.W.W.; Pezzuto, J.M.; Farnsworth, N.R.; Henderson, T.O. and Boye, G.L. (1993). Isolation of echinocystic acid-3- sulphate a new triterpene, from Tetrapluera tetraptera and evaluation of the mutagenic potential of molluscicidal extracts and isolates. J. Nat. Prod; 56, 1872-1877.

Sritularak B.; Likhitwitayawuid K.; Conrad, J.; Kraus, W. (2002). Flavonoids from the roots of millettia 
erythrocalyx. Phytochemistry; 61: 943-7.

Veitch, N.C., Sutton PS; Kite G.C. and Ireland H.E. (2003). Six new isoflavones and a 5-deoxyflavonol glycoside from the leaves of Ateleiaherbert-smithii. J. Nat. Prod; 66, 210-216.

Yamamoto S., Aizu E., Jiang H., Nakadate T., Kiyoto I., Wang J.C. and Kato R. (1991). The potent antitumor-promoting agent isoliquiritigenin. Carcinogenesis, 12 317-323.

Yu S.M. and Kuo S.C. (1995). Vasorelaxant effect of isoliquiritigenin, a novel soluble guanylate cyclase activator, in rat aorta. Br J Pharmacol. 114, 1587-94. 